\title{
Имитационная модемь
}

\section{дия исследования метода фазового пуска аппаратуры передачи данных}

\section{А. В. Щёголев}

Пензенский государственный университет, Россия, 440026 г. Пенза, ум. Красная, 40

\section{H. A. Ezорова}

Пензенский государственный университет, Россия, 440026 г. Пенза, ум. Красная, 40

Аннотация. Приведено описание имитационной модели, предназначенной дия проведения статистических исследований процедуры фазового пуска аппаратуры передачи данных.

К^ючевые слова: доступность информации, фазовый пуск аппаратуры передачи данных, имитационная модель.

\section{Simulation model to study the phase starting method for data transmission equipment}

\section{A. V. Shchegolev}

Penza State University, 40 Krasnaya Street, 440026, Penza, Russia

\section{N. A. Egorova}

Penza State University, 40 Krasnaya Street, 440026, Penza, Russia

Abstract. A description of the simulation model for statistical studies of phase starting of data transmission equipment is given.

Keywords: availability of information, phase starting of data transmission equipment, simulation model.

Для обеспечения доступности данных, передаваемых по радиоканалу, большую роль играет помехоустойчивость процедуры фазового пуска аппаратуры передачи данных. Для проведения экспериментальных исследований удобно использовать имитационное моделирование.

Имитационное моделирование позволяет проводить большой объем испытаний, имитировать различные внешние воздействия на модель, что позволяет получить сведения о поведении объекта моделирования. Имитация предназначена для построения некоторого идеализированного процесса функционирования системы, называемого имитационным процессом [1].

Процесс функционирования реальной системы распадается на ряд процессов функционирования отдельных объектов. Эти процессы протекают одновременно или параллельно. Задача программной имитации состоит в отображении параллельно протекающих процессов на один вычислительный процесс. Это отображение может быть выполнено различными способами в зависимости от задач и показателей эффективности.

Если поведение имитационной модели является адекватным, то ее создание составляет большой практический интерес [1].

Целью работы является разработка имитационной модели для проведения статистических исследований помехозащищенности процедуры фазового пуска.

В настоящее время особое внимание уделено двум основным вариантам построения устройств фазового пуска аппаратуры передачи данных: 
- с обнаружением ошибок и селекцией неискаженного участка последовательности;

- с исправлением ошибок методами позначного (порогового) декодирования [2-4].

Поэтому оба алгоритма должны быть реализованы в имитационной модели.

В качестве воздействий на процедуру синхронизации необходимо рассмотреть рассинхронизацию несущих частот устройства преобразования сигналов и воздействие белого гаусского шума в канале связи.

Имитационная модель была разработана на языке Си++. На рис. 1 показан интерфейс разработанной программы.

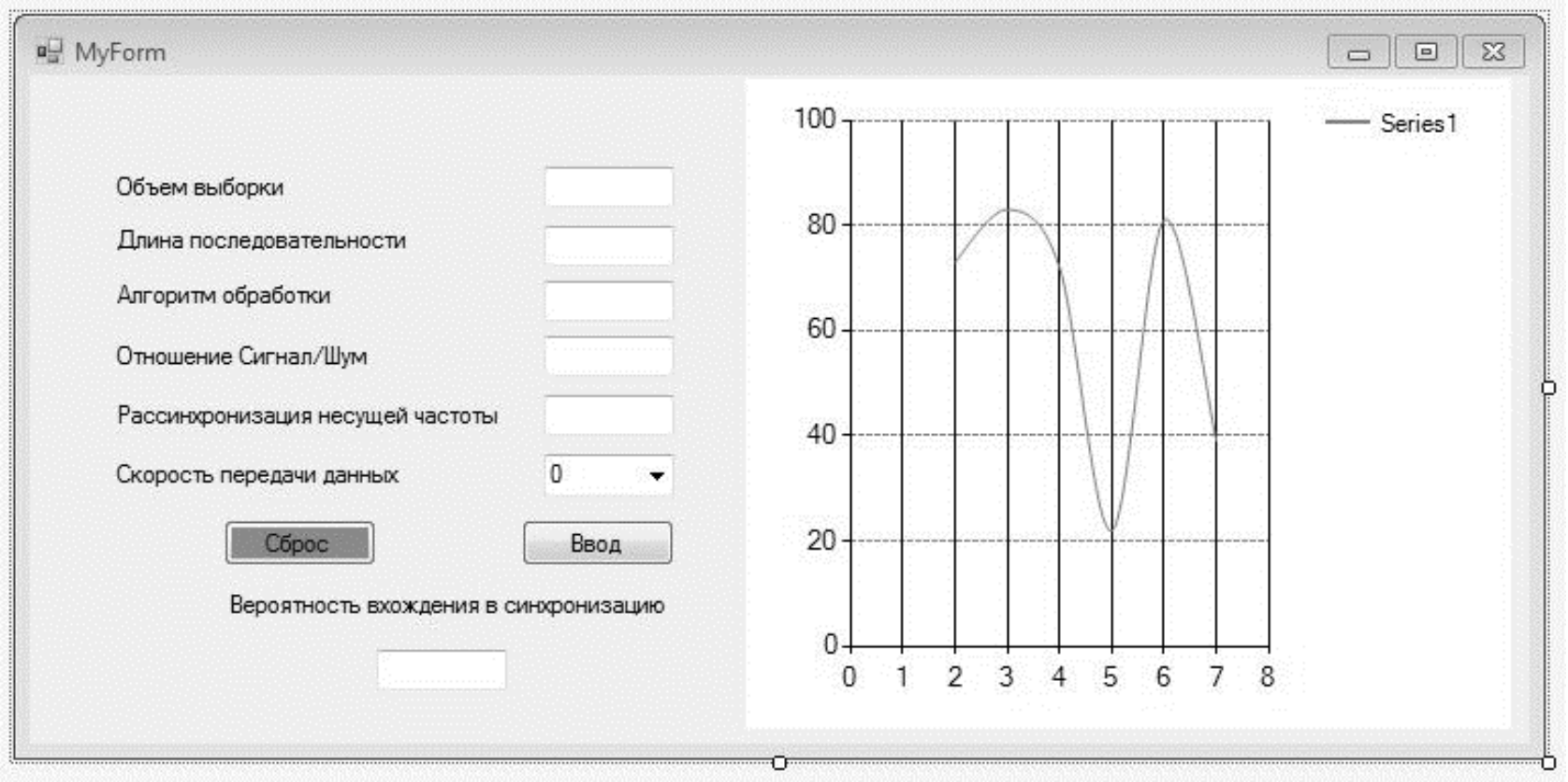

Рис. 1. Интерфейс разработанной программы

Интерфейс программы состоит из:

- шести полей для ввода информации;

- двух кнопок: «Сброс» и «Ввод»;

- одного поля для вывода информации;

- графика.

Перед началом работы необходимо заполнить шесть полей, такие как: «Объем выборки», «Длина последовательности», «Алгоритм обработки», «Отношение Сигнал/Шум», «Рассинхронизация несущей частоты», «Скорость передачи данных». В противном случае программа не выдаст результат. В поле «Скорость передачи данных» используется радиокнопка.

Радиокнопка - элемент управления, который позволяет пользователю выбрать один вариант из нескольких предложенных. Выбранное поле в данный момент обводится цветной рамкой.

Кнопка «Сброс» предназначена для полного стирания значений всех полей, что позволяет пользователю значительно экономить время при пользовании программой.

Кнопка «Ввод» предназначена для вывода результата программы в поле «Вероятность вхождения в синхронизацию» в виде вероятности, которая следом отмечается на графике.

В интерфейсе программы строится график зависимости вероятности вхождения в синхронизм от отношения «Сигнал/Шум» в канале связи. График, как и любая графическая информация, позволяет визуализировать информацию, т.е. превратить обычные числа в наглядную, понятную информацию. С помощью графиков легче и быстрее понять соотношение показателей, объектов, провести их быстрый сравнительный анализ.

Говорят, что модель адекватна оригиналу, если при ее интерпретации возникает «портрет», в высокой степени сходный с оригиналом.

До тех пор пока не решен вопрос, правильно ли отображает модель исследуемую систему (т.е. адекватна ли она), ценность модели нулевая [1].

Проверку адекватности проводят на всех этапах построения модели, начиная с самого первого этапа - концептуального анализа. Если описание системы будет составлено неадекватно реальной 
системе, то и модель, как бы точно она ни отображала описание системы, не будет адекватной оригиналу. Здесь сказано «как бы точно», так как имеется в виду, что вообще не существует математических моделей, абсолютно точно отображающих процессы, существующие в реальности [5].

Итак, можно говорить об адекватности модели в любой ее форме и оригинала, если:

- описание поведения, созданное на каком-либо этапе, достаточно точно совпадает с поведением моделируемой системы в одинаковых ситуациях;

- описание убедительно представительно относительно свойств системы, которые должны прогнозироваться с помощью модели.

Модель и объект подвергаются одинаковым воздействиям, и сравниваются их реакции. Если реакции одинаковы (в пределах допустимой точности), то делается вывод о том, что модель адекватна оригиналу.

Могут быть рекомендованы два основных подхода к оценке адекватности:

- по средним значениям откликов модели и системы;

- по дисперсиям отклонений откликов модели от среднего значения откликов систем.

Для проверки адекватности разработанной модели использовался первый подход.

Таким образом, можно сделать вывод, что разработанная имитационная модель адекватна и работоспособна.

\section{Бибциографический список}

1. Адекватность модели. - URL: https://studme.org/163940/informatika/adekvatnost_modeli (дата обращения: 07.10.2018).

2. А. с. 475744 . Устройство выделения рекуррентного синхросигнала с обнаружением ошибок / И. Ф. Хомич. Заявитель Пензенский завод - ВТУЗ при заводе «ВЭМ» ; опуб. 30.06.75, Бюл. № 24.

3. А. с. 262942. Устройство для выделения рекуррентного синхросигнала с исправлением ошибок / И. Ф. Хомич. Заявитель Пензенский завод - ВТУЗ при заводе «ВЭМ»; опуб. 04.11.70, Бюл. № 7.

4. А. с. 809591. Устройство для автоматического измерения характеристик дискретного канала связи / И. Ф. Хомич. Заявитель Пензенский завод - ВТУЗ при заводе «ВЭМ» ; опуб. 28.02.81, Бюл. №8.

5. Проверка адекватности модели. - URL: https://studopedia.ru/15_63080_proverka-adekvatnosti-modeli.html (дата обращения: 07.10.2018).

\section{щёгомев, А. В.}

Имитационная модель для исследования метода фазового пуска аппаратуры передачи данных / А. В. Щёголев, Н. А. Егорова // Инжиниринг и технологии. - 2018. Vol. 3(2). - DOI 10.21685/2587-7704-2018-3-2-4. 